\title{
Evaluation of anti-osteoporosis in ovariectomized Wistar rats treated with antler blood by synchrotron radiation X-ray fluorescence microprobe
}

\author{
Jianhong Yang ${ }^{\mathrm{a}, \mathrm{b}, *}$, Ruilin Wang ${ }^{\mathrm{b}}$, Yi Cao ${ }^{\mathrm{b}, \mathrm{c}}$, Yurong Fei ${ }^{\mathrm{b}}$, Yuying Huang ${ }^{\mathrm{d}}$, \\ Wei He ${ }^{\mathrm{d}}$ and Jing Liu ${ }^{\mathrm{a}}$ \\ ${ }^{a}$ School of Life Sciences, University of Science and Technology of China, Hefei 230026, China \\ ${ }^{\mathrm{b}}$ School of Life Sciences, Graduate University of CAS, Beijing 100049, China \\ ${ }^{\mathrm{c}}$ School of Life Sciences, Jiling University, Changchun 130000, China \\ ${ }^{\mathrm{d}}$ Institute of High Energy Physics, The Chinese Academy of Sciences, Beijing 100049, China
}

\begin{abstract}
To evaluate the anti-osteoporotic effect of antler blood, the relationship between the change of element content and the bone mineral density (BMD) increase in femur was investigated. Female Wistar rats were randomly divided into three groups: sham-operated group (SHAM, $n=5$ ), ovariectomized group (OVX, $n=5$ ) and ovariectomized group with antler blood treatment $(n=5)$. The femoral BMD was analyzed by dual-energy X-ray absorptiometry (DXA) and the element relative content was determined by synchrotron radiation X-ray fluorescence (SRXRF) microprobe. The results showed that the femoral BMD in ovariectomized rats was significantly lower than that of sham-operated rats $(p<0.05)$ but reversed by antler blood treatment $(p<0.05)$. A further study demonstrated that the relative contents of phosphorus $(\mathrm{P})$, calcium $(\mathrm{Ca})$, zinc $(\mathrm{Zn})$ and strontium (Sr) were obviously lower in ovariectomized rats compared to sham-operated rats but only the relative contents of $\mathrm{P}, \mathrm{Ca}$ and $\mathrm{Zn}$ were normalized by antler blood treatment $(p<0.05)$. Our experiments revealed that loss of element $\mathrm{Ca}, \mathrm{P}$, $\mathrm{Zn}$ and $\mathrm{Sr}$ was closely related to the BMD reduction in ovariectomized rats and the anti-osteoporotic effect of antler blood was mediated by increasing the contents of $\mathrm{P}, \mathrm{Ca}$ and $\mathrm{Zn}$.
\end{abstract}

Keywords: Element analysis, BMD, osteoporosis, femur, SRXRF

\section{Introduction}

The human skeleton is composed of organic matter, inorganic matter and water. Inorganic matter includes the macroelements $\mathrm{Ca}, \mathrm{P}, \mathrm{Na}, \mathrm{K}$ and the trace elements $\mathrm{Mg}, \mathrm{Mn}, \mathrm{Fe}, \mathrm{Cr}, \mathrm{Ni}, \mathrm{Cu}, \mathrm{Zn}, \mathrm{Se}, \mathrm{Sr}$ and so on. These elements are enveloped in organic protein collagen, influence the process of remodeling by affecting bone mineral crystal size, density and solubility and closely related to the bone structure $[1,2]$. Studies show that the decrease of bone mineral density (BMD) is a major risk factor leading to osteoporosis [3]. Osteoporosis is a disease characterized by low bone mass and microarchitectural deterioration of bone tissue, leading to increase bone fragility and fracture risk, and can be prevented by

\footnotetext{
${ }^{*}$ Corresponding author: Dr. Jianhong Yang, School of Life Sciences, Graduate University of Chinese Academy of Sciences (CAS), 19(A) Yuquan Road, Beijing 100049, P. R. China. Tel.: +86 010 88256349; Fax: +86 010 88256080; E-mail: yangjh@gucas.ac.cn.
} 
anti-osteoporotic drugs such as estrogen replacement therapy, parathyroid hormone and so on. Antler blood is a traditional Chinese herb medicine and our experiment showed that antler blood treatment could increase the BMD in ovariectomized rats which is considered to be a standard osteoporosis model similar to human postmenopausal osteoporosis due to estrogen deficiency. But little is known about the relationship between the change of element content and BMD increase in antler blood-treated ovariectomized rats.

Synchrotron radiation X-ray fluorescence (SRXRF) technique is being extensively applied in the fields of life science and medical science because it's more sensitive and less injurious to cell, and also has excellent characteristics such as very high brightness, collimation, polarization and lower bremsstrahlung which is the electromagnetic radiation produced by an accelerated electrically charged subatomic particle [4]. Using SRXRF technique, Zhang et al. [5] found that $\mathrm{Ca}, \mathrm{P}$ and $\mathrm{K}$ were the major elements of bone composition and obviously low in both spongy and cartilage zones of the femoral head slice in osteoporotic patient. The statistical analysis showed that $\mathrm{Ca}$ had good correlation with $\mathrm{P}, \mathrm{Zn}, \mathrm{Sr}$ and K. Fei et al. [6] reported that the relative mineral content of $\mathrm{Ca}, \mathrm{P}$ and $\mathrm{Zn}$ in streptozotocin (STZ)-induced diabetic femurs decreased significantly compared to controls $(p<0.01)$ and Ca correlated positively with $\mathrm{P}$, with Sr, with $\mathrm{Zn}$. The aim of our study is that the mineral content of femur is analyzed by SRXRF microprobe to assess its correlation with the BMD in ovariectomized rats treated with antler blood.

\section{Materials and methods}

\subsection{Sample preparation}

Fifteen 8-weeks-old female Wistar rats $(180 \pm 10 \mathrm{~g})$ were purchased from Vital River experimental animal technology Inc. (Beijing, China). Animals were divided into 3 groups randomly, acclimatized for one week before use, and had free access to feed and water. One group was sham operated (SHAM, group 1, $n=5$ ), and two groups were subjected to bilateral ovariectomy (OVX, groups 2 and $3, n=10$ ). After 4 weeks, one of OVX groups treated with antler blood $(4000 \mu 1 / \mathrm{kg}$ daily, group $3, n=5)$ orally for 10 weeks. At the end of the experiment, all the rats were sacrificed. The left femur was dissected out carefully, cleaned of soft tissue and stored in $10 \%$ formalin.

\subsection{Bone density}

Before the experiment, each left femur was picked out of $10 \%$ formalin and made it dry. The bone mineral density was determined by DXA (Excellplus, Norland Co., USA).

\subsection{Element analysis}

The scanning X-ray fluorescence microprobe analysis of left femur was performed using synchrotron radiation from the BEPC storage ring $(2.2 \mathrm{GeV}, 45-90 \mathrm{~mA})$ at Institute of High Energy Physics, CAS. A special set of adjustable slits was used to change the size of the excited X-ray beam. In our experiment, three of five femur samples in each group were randomly selected and fixed on the sample holder. Five points on each femur were scanned by SRXRF microprobe for element analysis (Fig. 1). The size of the microprobe was confined to $20 \times 20 \mu \mathrm{m}^{2}$. The element image of profile was performed point by point. 


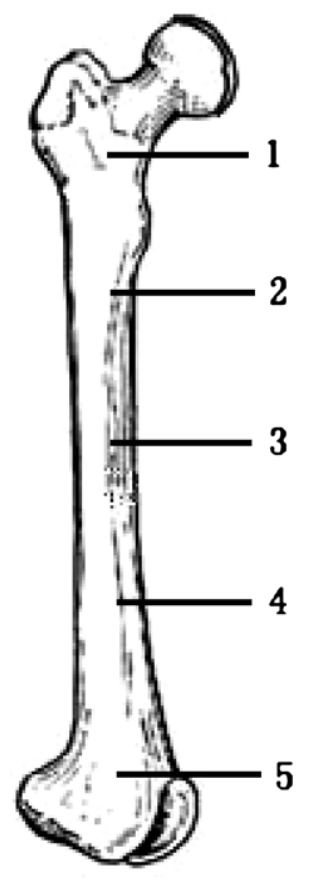

Fig. 1. The left femur. Five points were selected and scanned by SRXRF microprobe.

An ionization monitor chamber filled with nitrogen under normal pressure near the collimation system was used to measure the exciting radiation intensity. The exposure time was $100 \mathrm{~s}$ at a photon energy of $3.5-35 \mathrm{keV}$ for each point, and the length of scanning step in the experiments was $0.6 \mathrm{~cm}$. The scanner was driven by a motor driver, which was controlled by a computer. The $\mathrm{Si}(\mathrm{Li})$ detector worked under liquid nitrogen and was placed $4 \mathrm{~cm}$ from the samples with energy resolution about $165 \mathrm{eV}$ (HWFM) Mn K alpha $5.9 \mathrm{keV}$. The detector was located at $90^{\circ}$ with respect to the beam direction. Because the synchrotron radiation was plane polarized with the electric vector in the plane of the electron orbits in the storage ring, there was a minimum Compton scattering background when the detector was located at $90^{\circ}$. The associated electronics was composed of a pulsed optical preamplifier, spectroscopy amplifier and pulse pile-up rejector. Then, the signals were connected to an Oxford multichannel analyzer for data acquisition and analysis. Data of spectra were processed by using the program AXIL and the relative intensity was obtained by comparing the element X-ray fluorescence (XRF) intensity of the sample with that of Ar. The normalized intensity was for estimating the relative content of elements. A typical energy spectrum of the femur sample was shown in Fig. 2.

\subsection{Statistical analysis}

Statistical analysis was carried out using SPSS program (Version 10.0). Results were expressed as mean $\pm \mathrm{SD}$ (standard deviation). Comparisons between groups were made by One-Way ANOVA. Pearson's correlation test was used for correlation analysis. The statistical significance was set if the $p$-value was less than 0.05 or 0.01 . 


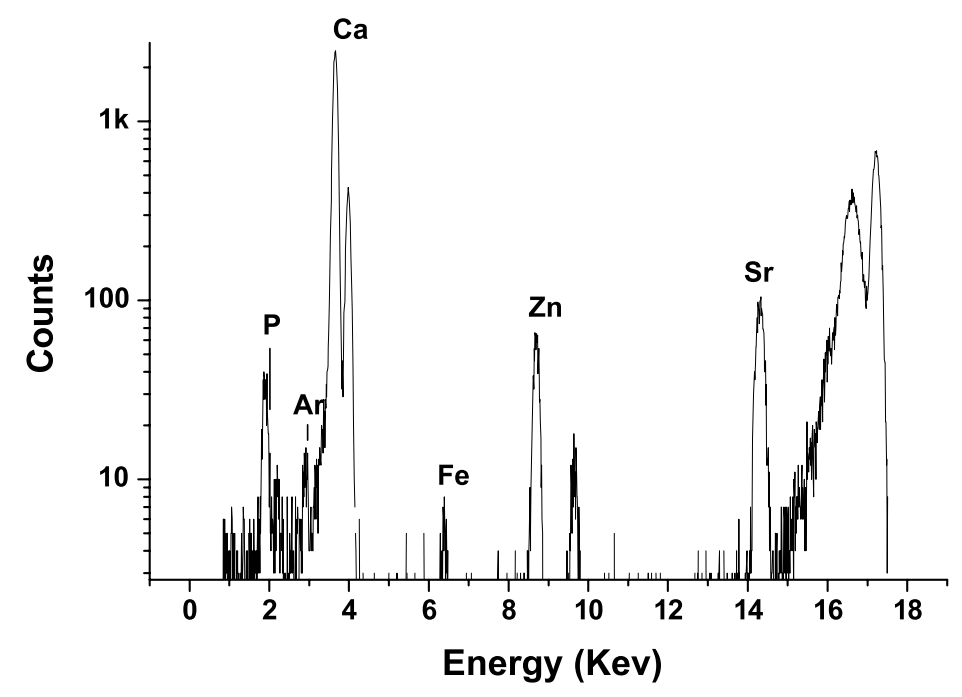

Fig. 2. A typical energy spectrum of the left femur sample is shown.

\section{Results}

\subsection{Bone density}

The femoral BMD in OVX group (group 2) was significantly lower than that in SHAM group (group 1) $(p<0.05)$ but reversed by antler blood treatment (group 3) $(p<0.05)$ (Fig. 3).

\subsection{Element analysis}

Using SRXRF microprobe, the results showed that the relative contents of $\mathrm{P}, \mathrm{Ca}, \mathrm{Zn}$ and $\mathrm{Sr}$ on femur in OVX group (group 2) were obviously lower than that in SHAM group (group 1) $(p<0.05)$. However, the relative contents of $\mathrm{P}, \mathrm{Ca}$ and $\mathrm{Zn}$ could be reserved by antler blood treatment (group 3) (Figs 4-7).

The correlations between the element relative contents in SHAM group were shown in Table 1. There were very good positive correlation between $\mathrm{P}$ and $\mathrm{Ca}(R=0.985, p<0.01), \mathrm{P}$ and $\mathrm{Zn}(R=0.918$, $p<0.05), \mathrm{P}$ and $\mathrm{Sr}(R=0.899, p<0.05), \mathrm{Ca}$ and $\mathrm{Zn}(R=0.964, p<0.01), \mathrm{Ca}$ and $\mathrm{Sr}(R=0.936$, $p<0.05), \mathrm{Zn}$ and $\mathrm{Sr}(R=0.983, p<0.01)$ in sham operated group. But there were no obviously positive correlation between element contents in other two groups.

\section{Discussion}

At present, many anti-osteoporotic drugs can increase the BMD, but little is known about the relationship between the BMD increase and the change of element content after treating with them. Our results showed that the low BMD $(p<0.05)$ in OVX rats was accompanied by decrease of $\mathrm{Ca}, \mathrm{P}, \mathrm{Zn}$ and $\mathrm{Sr}$ contents $(p<0.05)$. However, the BMD could be reserved along with the increase of the relative contents of $\mathrm{Ca}, \mathrm{P}$ and $\mathrm{Zn}$ after antler blood treatment $(p<0.05)$. Furthermore, statistical analysis in SHAM group showed that there were highly positive correlations between $\mathrm{Ca}$ and $\mathrm{P}, \mathrm{Zn}$ and $\mathrm{Sr}$ contents. 


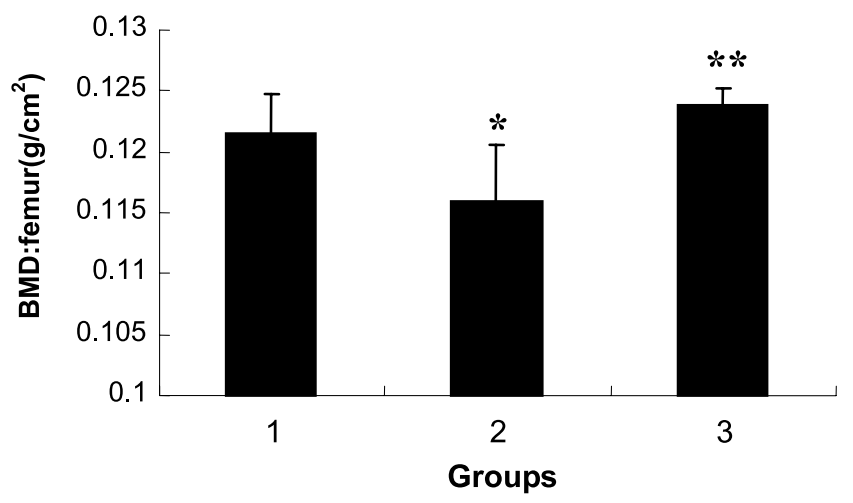

Fig. 3. Bone mineral density of femur. Group 1 is SHAM. Group 2 is $\mathrm{OVX}\left({ }^{*} p<0.05\right.$, vs. group 1$)$. Group 3 is OVX treated with antler blood $(* * p<0.05$, vs. group 2$)$. BMD: bone mineral density.

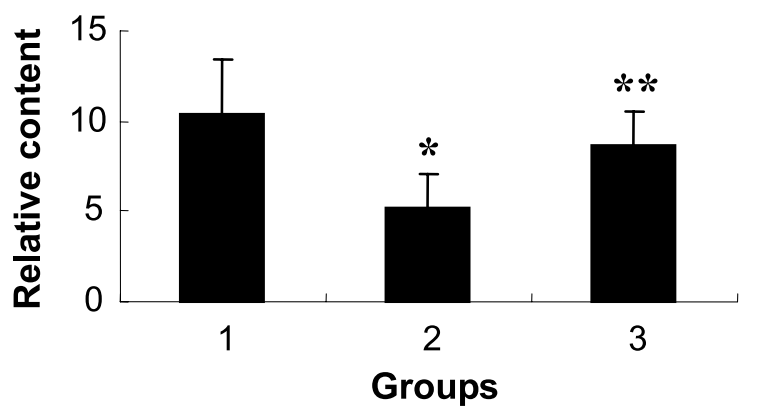

Fig. 4. The relative content of P by SRXRF. Group 1 is SHAM. Group 2 is OVX ( $* p<0.01$, vs. group 1 ). Group 3 is OVX treated with antler blood $(* * p<0.05$, vs. group 2$)$.

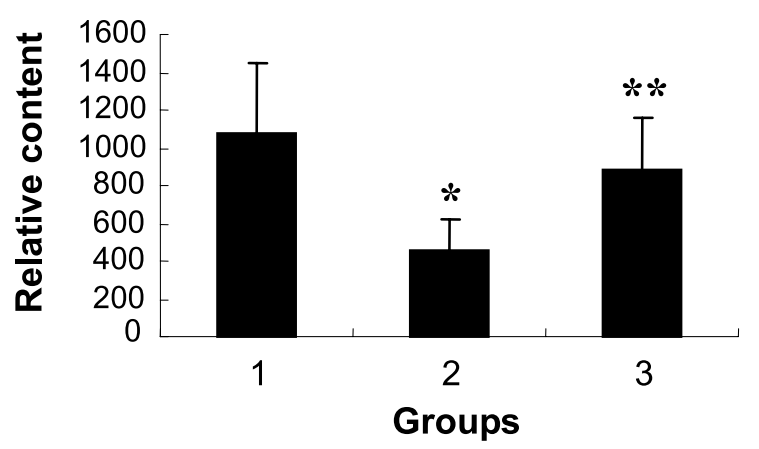

Fig. 5. The relative content of Ca by SRXRF. Group 1 is SHAM. Group 2 is $\mathrm{OVX}\left({ }^{*} p<0.05\right.$, vs. group 1$)$. Group 3 is $\mathrm{OVX}$ treated with antler blood $(* * p<0.05$, vs. group 2$)$.

As we known, bone is a dynamic tissue constantly remodeled throughout life. The structure of bone consists of a solid mineral substance in close association with an organic compound. The main mineral component of bone is an imperfectly crystalline hydroxyapatite $\left[\mathrm{Ca}_{10}\left(\mathrm{PO}_{4}\right)_{6}(\mathrm{OH})_{2}\right]$, which comprises $1 / 4$ the volume and $1 / 2$ the mass of the normal adult bone [7]. Therefore $\mathrm{Ca}$ is considered the most important nutrient concerning bone health and its deficiency can lead to a decrease in BMD as well as a predisposition to osteoporosis. Epidemiological evidences show that $\mathrm{Ca}$ intake was positively correlated 


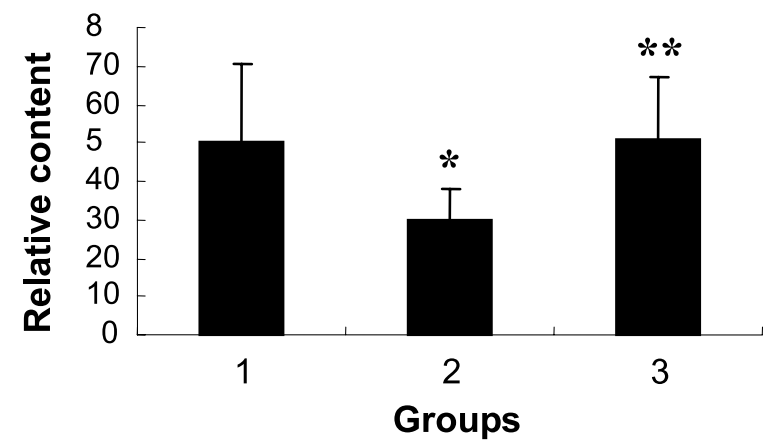

Fig. 6. The relative content of Zn by SRXRF. Group 1 is SHAM. Group 2 is $\mathrm{OVX}\left({ }^{*} p<0.05\right.$, vs. group 1$)$. Group 3 is OVX treated with antler blood $(* * p<0.05$, vs. group 2$)$.

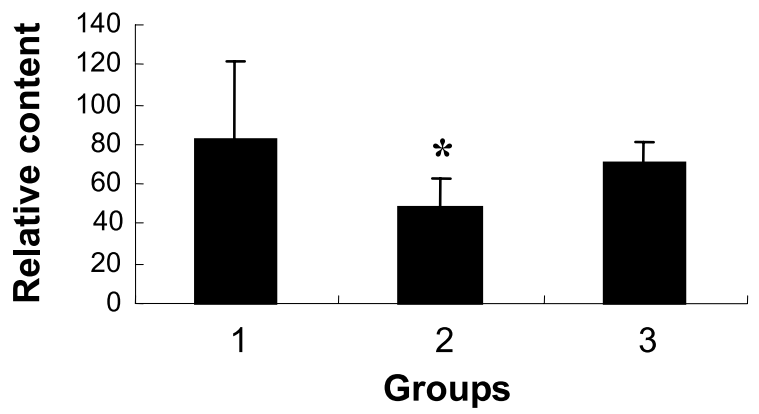

Fig. 7. The relative content of Sr by SRXRF. Group 1 is SHAM. Group 2 is OVX ( ${ }^{*} p<0.05$, vs. group 1 ). Group 3 is OVX treated with antler blood.

with BMD [8,9]. An adequate intake of Ca determined the development of a maximum bone mass at the end of the adolescence period, and ameliorated the progressive loss of this bone mass with age [10]. In addition, $\mathrm{P}$ is second to $\mathrm{Ca}$ in abundance in the human body with $85 \%$ bound to the skeleton [11]. P regulates the bone formation, inhibits the bone resorption, and acts as one of anti-osteoporosis nutrients [12]. Study revealed that $P$ also affected the regulation of calcium metabolism [13]. Supply with $\mathrm{Ca}$ and $\mathrm{P}$ was already considered as a treatment of osteoporosis [14]. Zhang et al. and Fei et al. [5,6] also found that the element $\mathrm{Ca}$ and $\mathrm{P}$ in femur were obviously low in patients and rats with osteoporosis. In our study, the results demonstrated that the relative contents of $\mathrm{P}$ and $\mathrm{Ca}$ as well as the femoral BMD in ovariectomized rats were significantly lower than that in sham-operated group $(p<0.05)$ but normalized by antler blood treatment $(p<0.05)$ (Figs 3-5). Meanwhile, statistical analysis showed that there was a very good positive correlation between $\mathrm{P}$ and $\mathrm{Ca}(R=0.985, p<0.01)$ (Table 1$)$, consistent with Zhang's report. Hence, the results revealed that loss of element $\mathrm{P}$ and $\mathrm{Ca}$ was closely associated with the BMD decrease and it's very important that antler blood treatment could increase the BMD by enhancing the relative contents of $\mathrm{P}$ and $\mathrm{Ca}$.

Additionally, other trace minerals have effects on bone biology by affecting bone mineral crystal site, density, and solubility [1,2]. Bone has one of the highest concentrations of zinc of all tissues and zinc is essential for the growth, development, and maintenance of healthy bones [15]. Experimental data suggested that $\mathrm{Zn}$ stimulated bone protein synthesis and bone formation by increasing the activity of alkaline phosphatase which was involved in bone mineral deposition and also inhibited bone resorption 
Table 1

Correlation between element contents in femur of sham-operated group

\begin{tabular}{lllll}
\hline & \multicolumn{1}{c}{$\mathrm{P}$} & \multicolumn{1}{c}{$\mathrm{Ca}$} & \multicolumn{1}{c}{$\mathrm{Zn}$} & \multicolumn{1}{c}{$\mathrm{Sr}$} \\
\hline $\mathrm{P}$ & 1 & $0.985^{* *}$ & $0.918^{* *}$ & $0.899^{*}$ \\
$\mathrm{Ca}$ & $0.985^{* *}$ & 1 & $0.964^{* *}$ & $0.936^{*}$ \\
$\mathrm{Zn}$ & $0.918^{*}$ & $0.964^{* *}$ & 1 & $0.983^{* *}$ \\
$\mathrm{Sr}$ & $0.899^{*}$ & $0.936^{*}$ & $0.983^{* *}$ & 1 \\
\hline
\end{tabular}

*Correlation is significant at the 0.05 level.

**Correlation is significant at the 0.01 level.

by reducing osteoclast activity [16-18]. Furthermore, Zn regulated secretion of calcitonin from thyroid gland which was presumed to play a role in regulating calcium metabolism and calcium transport [19]. Rossi and colleagues [20] revealed that zinc deficiency in growing rats resulted in reduced bone growth and bone volume. Atik [21] reported that men suffering from senile osteoporosis had lower serum zinc and lower femur zinc compared with control patients. Some studies showed that $\mathrm{Zn}$ supplements added to the diet could exert a positive influence on human bone linear growth [22,23]. In our present experiment, statistical analysis showed that there was a very good positive correlation between $\mathrm{Ca}$ and $\mathrm{Zn}$ ( $R=0.964, p<0.01$ ) (Table 1). We also found that the relative content of $\mathrm{Zn}$ and the femoral BMD decreased in ovariectomized group compared to sham-operated group but reserved by antler blood treatment $(p<0.05)$ (Figs 3 and 6). Furthermore, we concluded that the increase of trace element $\mathrm{Zn}$ after antler blood treatment was positively related to high BMD.

$\mathrm{Sr}$ is another trace element that could regulate the bone balance and increase in bone mass [24,25]. Strontium was mainly adsorbed on the crystal surface in bone, and only one in ten calcium cations in the apatite crystal was found to be replaced by strontium in vivo [26]. Strontium ranelate, a novel agent containing two stable strontium atoms, has been licensed in United Kingdom for the treatment of osteoporosis [27]. Studies in vivo showed that strontium ranelate reduced bone resorption by decreasing preosteoclast differentiation and osteoclastic activity [28-30] and increased bone formation by promoting osteoblast replication [31-33] and activity [34]. As an effective anti-osteoporotic drug, strontium ranelate could activate the calcium-sensing receptor in bone cells, resulting in activation of inositol trisphosphate production and mitrogen-activated protein kinases signaling [35,36]. In our experiment, we found that the relative content of $\mathrm{Sr}$ and the femoral BMD decreased in ovariectomized group compared to sham-operated group $(p<0.05)$ but the relative content of $\mathrm{Sr}$ did not increase obviously after antler blood treatment (Figs 3 and 7) although $\mathrm{Sr}$ had very good positive correlation with $\mathrm{P}, \mathrm{Ca}$ and $\mathrm{Zn}$ (Table 1).

In conclusion, using SRXRF technique, we found that loss of the relative contents of $\mathrm{Ca}, \mathrm{P}, \mathrm{Zn}$ and $\mathrm{Sr}$ accounted for the BMD decrease in ovariectomized rats. However antler blood treatment could restore the BMD by increasing the mineral contents of $\mathrm{Ca}, \mathrm{P}$ and $\mathrm{Zn}$. Hence, dietary antler blood supplements may be useful for preventing osteoporosis.

\section{Acknowledgement}

This work is supported by the Scientific Research Foundation of Graduate University of Chinese Academy of Sciences (No. Y1016 and No. 055101FM03). 


\section{References}

[1] F. Bronner, Disorder of Mineral Metabolism, Vol. II, Academic Press, New York, 1981.

[2] P.D. Saltman and L.G. Strause, The role of trace minerals in osteoporosis, J. Am. Coll. Nutr. 12 (1993), 384-389.

[3] S.L. Meryl, Metabolic bone diseases in text book of rheumatology, 5th edn, in: K. Harris and R. Sludge, eds, Saunders, London, 1997.

[4] S.X. Kang, X. Sun, X. Ju, Y.Y. Huang, K. Yao, Z.Q. Wu and D.C. Xian, Measurement and calculation of escape peak intensities in synchrotron radiation X-ray fluorescence analysis, Nuclear Instruments and Methods in Physics Research B 192 (2002), 365-369.

[5] Y.X. Zhang, F. Cheng, D. Li, Y.S. Wang, G.L. Zhang, W.S. Liao, T.T. Tang, Y.Y. Huang and W. He, Investigation of elemental content distribution in femoral heads slice with osteoporosis by SRXRF microprobe, Biol. Trace Elem. Res. 103 (2005), 177-185.

[6] Y.R. Fei, M. Zhang, M. Li, Y.Y. Huang, W. He, W.J. Ding and J.H. Yang, Element analysis in femur of diabetic osteoporosis model by SRXRF microprobe, Micron 38 (2007), 637-642.

[7] C. Robert, Bone, Cornell University Medical College, 1999.

[8] T.B. Basabe, M.C. Mena Valverde, V.M. Faci, V.A. Aparicio, A.M. Lopez Sobaler and R.M. Ortega Anta, The influence of calcium and phosphorus intake on bone mineral density in young women, Arch. Latinoam. Nutr. 54 (2004), $203-208$.

[9] S. Sasaki, Calcium, magnesium, and potassium as dietary nutrients, Clin. Calcium 16 (2006), 110-115.

[10] NIH Consensus Conference, NIH Consensus Development Panel on Optimal Calcium Intake, JAMA 272 (1994), 19421947.

[11] J.Z. Ilich and J.E. Kerstetter, Nutrition in bone health revisited: a story beyond calcium, J. Am. Coll. Nutr. 19 (2000), 715-737.

[12] A. Kawaura, Y. Nishida and E. Takeda, Phosphorus intake and bone mineral density (BMD), Clin. Calcium 15 (2005), $1501-1506$

[13] M. Koshihara, S. Katsumata, M. Uehara and K. Suzuki, Effects of dietary phosphorus intake on bone mineralization and calcium absorption in adult female rats, Biosci. Biotechnol. Biochem. 69 (2005), 1025-1028.

[14] R.P. Heaney, Phosphorus nutrition and the treatment of osteoporosis, Mayo Clin. Proc. 79 (2004), 91-97.

[15] M.J. Yamaguchi, Role of zinc in bone formation and bone resorption, J. Trace Elem. Exp. Med. 11 (1998), 119-135.

[16] M. Yamaguchi and R. Yamaguchi, Action of zinc on bone metabolism in rats. Increase in alkaline phosphatase activity and DNA content, Biochemical Pharmacology 35 (1986), 773-777.

[17] S. Kishi and M. Yamaguchi, Inhibitory effects of zinc compounds on osteoclast-like cell formation in mouse marrow cultures, Biochemical Pharmacology 48 (1994), 1225-1230.

[18] S. Kishi, Y. Segawa and M. Yamaquchi, Histomorphological confirmation of the preventive effect of beta-alanyl-Lhistidine zinc on bone loss in on ovariectomized rats, Biol. Pharm. Bull. 17 (1994), 862-865.

[19] O. Itani and R.C. Tsang, Bone disease, in: Clinical Chemistry: Theory, Analysis, and Correlation, 3rd edn, L.A. Kaplan and A.J. Desce, eds, Mosby London, 1996, pp. 528-524.

[20] L. Rossi, S. Migliaccio, A. Corsi, M. Marzia, P. Bianco, A. Teti, L. Gambelli, S. Cianfarani, F. Paoletti and F. Branca, Reduced growth and skeletal changes in zinc-deficient growing rats are due to impaired growth plate activity and inanition, J. Nutr. 131 (2001), 1142-1146.

[21] O.S. Atik, Zinc and senile osteoporosis, J. Am. Geriatr. Soc. 31 (1983), 790-791.

[22] N.M. Diaz-Gomez, E. Domenech, F. Barroso, S. Castells, C. Cortabarria and A. Jimenez, The effect of zinc supplementation on linear growth, body composition, and growth factors in preterm infants, Pediatrics 111 (2003), 1002-1009.

[23] M. Merialdi, L.E. Caulfield, N. Zavaleta, A. Figueroa, K.A. Costigan, F. Dominici and J.A. Dipietro, Randomized controlled trial of prenatal zinc supplementation and fetal bone growth, Am. J. Clin. Nutr. 79 (2004), 826-830.

[24] M.D. Grynpas and P.J. Marie, Effects of low doses of strontium on bone quality and quantity in rats, Bone 11 (1990), 313-319.

[25] M.D. Grynpas, E. Hamilton, R. Cheung, Y. Tsouderos, P. Deloffre, M. Hott and P.J. Marie, Strontium increases vertebral bone volume in rats at a low dose that does not induce detectable mineralization defect, Bone 18 (1996), 253-259.

[26] G. Boivin, P. Deloffre, B. Perrat, G. Panczer, M. Boudeulle, Y. Mauras, P. Allain, Y. Tsouderos and P.J. Meunier, Strontium distribution and interactions with bone mineral in monkey illiac bone after strontium salt (S12911) administration, J. Bone Miner. Res. 11 (1996), 1302-1311.

[27] I. Fogelman and G.M. Blake, Strontium ranelate for the treatment of osteoporosis, BMJ 330 (2005), 1400-1401.

[28] E. Canalis, M. Hott, P. Deloffre, Y. Tsouderos and P.J. Marie, The divalent strontium salt S12911 enhances bone cell replication and bone formation in vitro, Bone 18 (1996), 517-523.

[29] R. Baron and Y. Tsouderos, In vitro effects of S12911-2 on osteoclast function and bone marrow macrophage differentiation, Eur. J. Phamacol. 450 (2002), 11-17.

[30] N. Takahashi, T. Sasaki, Y. Tsouderos and T. Suda, S12911-2 inhibits osteoclastic bone resorption in vitro, J. Bone Miner. Res. 18 (2003), 1082-1087. 
[31] P. Delannoy, D. Bazot and P.J. Marie, Long-term treatment with strontium ranelate increases vertebral bone mass without deleterious effect in mice, Metabolism 51 (2002), 906-911.

[32] M. Hott, P. Deloffre, Y. Tsouderos and P.J. Marie, S12911-2 reduced bone loss induced by short-term immobilization in rats, Bone 33 (2003), 115-123.

[33] P. Ammann, V. Shen, B. Robin, Y. Mauras, J.P. Bonjour and R. Rizzoli, Strontium ranelate improves bone resistance by increasing bone mass and improving architecture in intact female rats, J. Bone Miner. Res. 19 (2004), 2012-2020.

[34] P.J. Marie, Strontium as therapy for osteoporosis, Curr. Opin. Pharmacol. 5 (2005), 633-636.

[35] E.M. Brown, Is the calcium receptor a molecular target for the actions of strontium on bone?, Osteoporos. Int. 14 (2003), S25-S34.

[36] J. Coulombe, H. Faure, B. Robin and M. Ruat, In vitro effects of strontium ranelate on the extracellular calcium-sensing receptor, Biochem. Biophys. Res. Commun. 323 (2004), 1184-1190. 


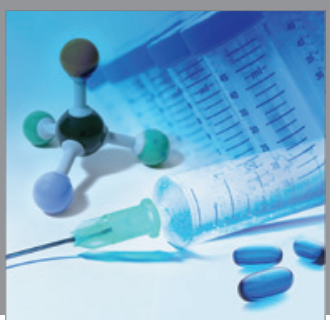

International Journal of

Medicinal Chemistry

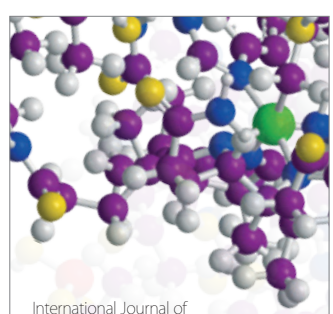

Carbohydrate Chemistry

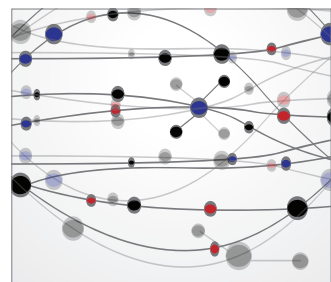

The Scientific World Journal
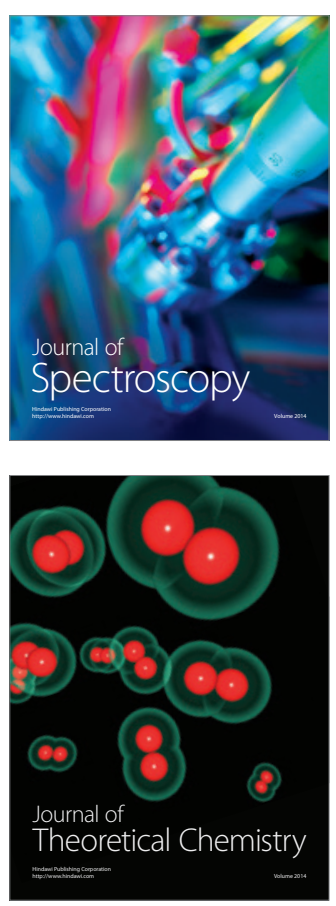
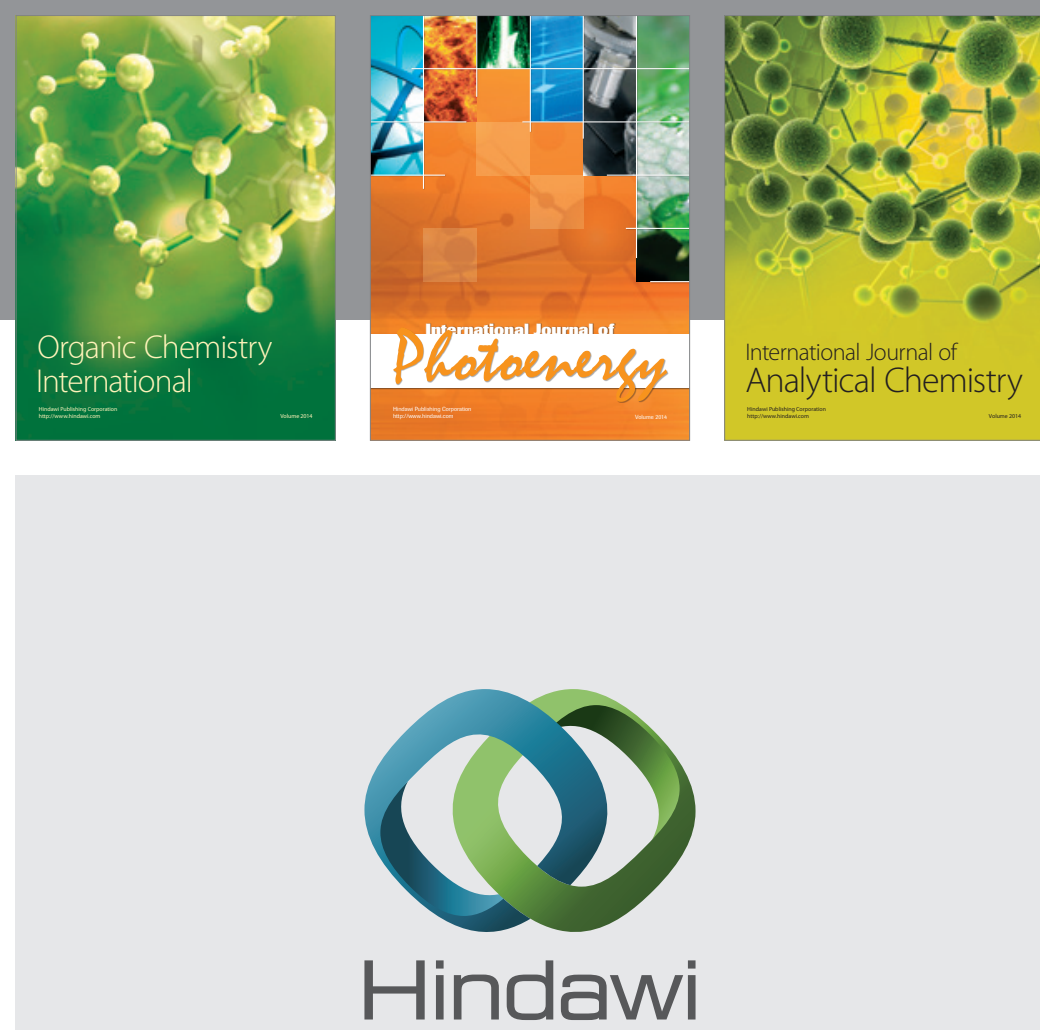

Submit your manuscripts at

http://www.hindawi.com
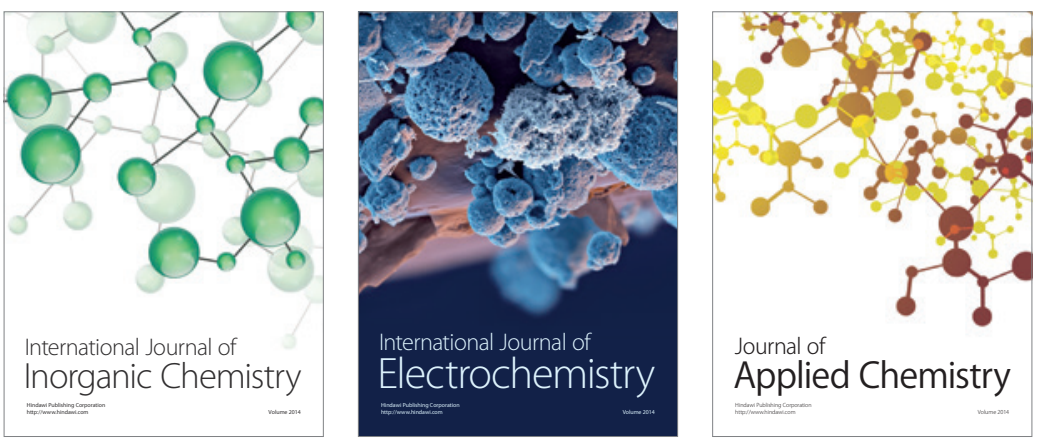

Journal of

Applied Chemistry
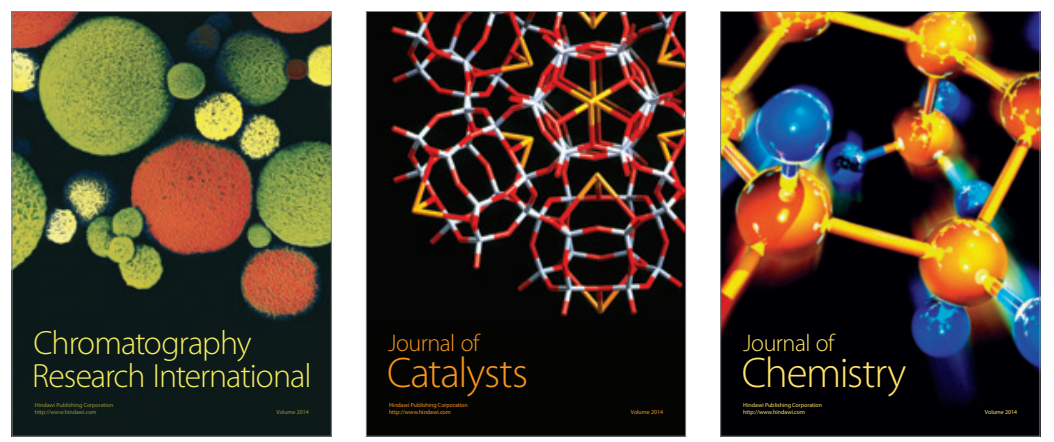
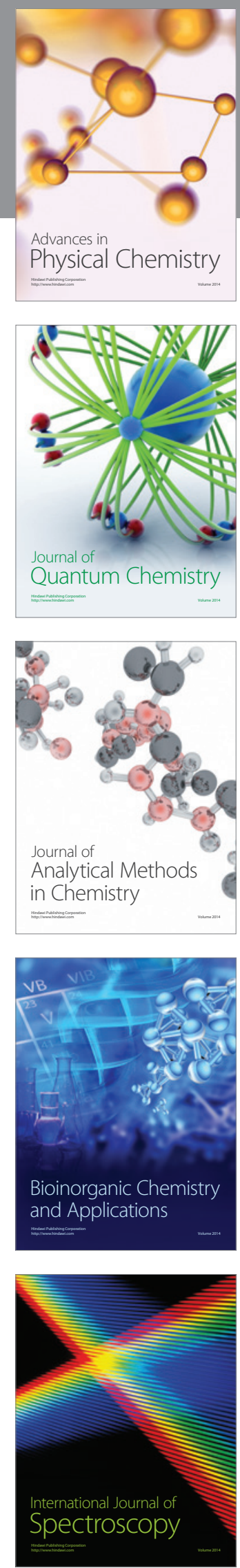